\title{
Interdisciplinaridade ambiental e democracia pluralista: uma reflexão a partir do conceito de agonismo de Chantal Mouffe
}

\author{
Environmental interdisciplinarity and pluralist \\ democracy: a reflection based on Chantal Mouffe's \\ concept of agonism
}

\author{
Gabriel Bandeira Coelho" \\ Jalcione Almeida ${ }^{* *}$ (D)
}

\section{RESUMO}

O presente artigo propõe uma nova definição ao conceito de interdisciplinaridade, especialmente no âmbito das ciências ambientais no Brasil, com vistas a demonstrar que a tentativa de dar sentido e significado ao termo está totalmente aberta e em constante disputa. Assim, este texto define a interdisciplinaridade ambiental nos termos de uma democracia pluralista, conforme exposta por Chantal Mouffe em sua teoria do discurso, ao conceituar o jogo político das sociedades democráticas a partir do conceito de agonismo. Esse conceito pressupõe a luta adversarial, sem a possibilidade de consensos como pano de fundo de toda e qualquer trama discursiva. Nessa sequência, se é factível definir a interdisciplinaridade como um campo político e, portanto, discursivo, pode-se pensar em defini-la como uma democracia pluralista, uma vez que determinado espaço que se diz interdisciplinar, afirma-se, é formado por diversas e distintas disciplinas (discursos), as quais se inter-relacionam por meio de tensões agônicas, e até mesmo antagônicas, em prol da hegemonização de suas demandas. ${ }^{\bullet}$

Palavras-chave: discurso, interdisciplinaridade, questões ambientais, hegemonia, democracia pluralista.

\footnotetext{
* Instituto Federal Catarinense, Brusque, SC, Santa Catarina.

** Universidade Federal do Rio Grande do Sul, Porto Alegre, RS, Brasil.

${ }^{\diamond}$ Esta reflexão é decorrente de uma pesquisa mais ampla sobre o tema da interdisciplinaridade e o lugar dos sociólogos nos programas de pós-graduação em Ciências Ambientais no Brasil. Para mais detalhes, ver Coelho $(2018,2020)$.
} 


\begin{abstract}
This article proposes a new definition of interdisciplinarity, especially in the scope of environmental sciences in Brazil, in order to demonstrate that the attempt to give sense and meaning to the term is totally open and permanently in dispute. Thus, this text aims to define environmental interdisciplinarity in terms of a pluralistic democracy, as exposed by Chantal Mouffe in her theory of discourse, when conceptualizing the political game of democratic societies based on the concept of agonism. This concept presupposes an adversarial struggle that does not make room for consensus, as a background for every discursive exchange. Following, if it is feasible to define interdisciplinarity as a political and, therefore, discursive field, one can think of defining it as a pluralistic democracy, since a space said to be interdisciplinary is formed by several and distinct disciplines (discourses), which are related through agonistic, and even antagonistic, tensions pressing for hegemonization of their demands.
\end{abstract}

Keywords: discourse, interdisciplinarity, environmental issues, hegemony, pluralistic democracy.

\title{
Introdução
}

O século 20, em nível global, foi marcado por ampla e complexa dinâmica social, em especial nas dimensões política, da economia e da ciência. O surgimento da mecânica quântica no início do referido século (em conjunto com a Teoria da Relatividade de Einstein), as duas grandes guerras mundiais, a depressão econômica de 1929, a Guerra Fria, a Declaração Universal dos Direitos Humanos, em 1948, o desenvolvimento da cibernética na década de 1940, a emergência da chamada sociedade do conhecimento na década de 1970, juntamente ao neoliberalismo econômico, além da nanotecnologia atualmente, dentre outros eventos não menos importantes, revelam as grandes transformações que vêm ocorrendo nas sociedades contemporâneas, sobretudo no que diz respeito à "questão ambiental". ${ }^{1}$

\footnotetext{
${ }^{1}$ Ambiente aqui é entendido como "o conjunto de meios naturais ou artificializados da ecosfera onde os humanos se instalaram, que exploram e administram e o conjunto dos meios não antropizados necessários à sua sobrevivência. Estes meios são caracterizados a) por sua geometria, seus componentes físicos, químicos, biológicos e humanos e a distribuição espacial destes componentes; b) pelos processos de transformação, de ação ou de interação implicando estes componentes, fazendo-os mudar no espaço e no tempo; e c) por suas múltiplas dependências em relação às ações humanas” (Jollivet \& Pavé, 1993 apud Almeida, 2016, p. 14). Quanto à "questão ambiental", sua caracterização encontra-se mais adiante neste texto.
} 
A partir das densas modificações ocorridas no campo ${ }^{2}$ do conhecimento e no espaço social, além das transformações na relação entre humanos e natureza, a pesquisa científica tem apontado, há algumas décadas, sobretudo a partir da segunda metade do século passado, a fragilidade, instabilidade e possível esgotamento da episteme cartesiana, anunciando sua (potencial) crise e a emergência de um novo paradigma, o da complexidade. De acordo com Morin (2006, p. 7), o pensamento complexo "religa não apenas os domínios separados do conhecimento, como também conceitos antagônicos como ordem e desordem, certeza e incerteza, a lógica e a transgressão lógica”. Morin (2006) afirma, ainda, que o pensamento complexo tece em conjunto (complexus) e abraça (complexere); "tece" e "abraça” os fenômenos como parte de um único processo de relações, sem que haja separação e compartimentação como no modelo cartesiano preconizado pelos cânones da ciência moderna.

Diante disso, o presente artigo propõe uma nova definição ao conceito de interdisciplinaridade, ${ }^{3}$ especialmente no âmbito das ciências ambientais, ${ }^{4}$ com vistas a demonstrar que a tentativa de dar sentido e significado ao termo está totalmente aberta e em constante disputa. Assim, este texto propõe-se a definir a interdisciplinaridade ambiental nos termos de uma democracia pluralista, conforme exposta por Chantal Mouffe em sua teoria do discurso, ao conceituar o jogo político das sociedades democráticas a partir do conceito de agonismo. Dessa maneira, o conceito de agonismo

\footnotetext{
${ }^{2}$ No sentido empregado por Bourdieu (2013).

3 "Há um leque de elementos que definem esses conceitos e até mesmo a literatura sobre o tema traz uma série de outras subdivisões conceituais no que tange à integração entre distintos saberes. "disciplinarização cruzada”, "codisciplinaridade", "interdisciplinaridade auxiliar", "interdisciplinaridadecomplementar”, "interdisciplinaridadecompósita”, "interdisciplinaridade de engrenagem”, "interdisciplinaridade estrutural”, "interdisciplinaridade heterogénea”, "interdisciplinaridade linear", "interdisciplinaridade restritiva”, "interdisciplinaridade unificadora”, "multidisciplinaridade”, "pluridisciplinaridade”, "transdisciplinaridade", "transdisciplinaridade ampliada" são alguns dos termos que têm sido propostos na busca por definir as categorias que caracterizam os diversos graus de diálogo existentes entre as diferentes áreas do conhecimento científico" (Coelho, 2015, p. 143). Desse modo, a definição de interdisciplinaridade como democracia pluralista, ora proposta, visa "resolver", de modo geral, tal "confusão" de conceitos. Logo, toda e qualquer integração disciplinar num esforço coletivo de buscar soluções a problemas de natureza complexa pode ser considerada interdisciplinar e, portanto, democraticamente pluralista. Não há, entende-se, como quantificar ou medir graus de "interação", nem mesmo por probabilidades. Isso ocorre, argumenta-se, porque os conceitos são abstratos e se encontram numa dimensão ontológica, diferentemente de quando utilizados para explicar determinada realidade, sendo traduzidos na dimensão ôntica (no cotidiano dos agentes sociais) na busca por conferir sentido às práticas sociais, nesse caso, à prática interdisciplinar.

${ }^{4}$ Usa-se, aqui, ciências ambientais e interdisciplinaridade ambiental como conceitos equivalentes.
} 
pressupõe a luta adversarial, sem a possibilidade de consensos - como nas teorias liberais sobre democracia - como pano de fundo de toda e qualquer trama discursiva. Se é factível definir a interdisciplinaridade como um campo político e, portanto, discursivo, pode-se pensar em defini-la como uma democracia pluralista, uma vez que determinado espaço que se diz interdisciplinar, afirma-se, é formado por diversas e distintas disciplinas (discursos), as quais se inter-relacionam por meio de tensões agônicas e até mesmo antagônicas em prol da hegemonização de suas demandas.

Nesse sentido, este artigo está estruturado da seguinte maneira: a primeira seção, intitulada "A questão ambiental como objeto complexo e o caminho à interdisciplinaridade", traz à tona um ligeiro debate sobre como a questão ambiental tornou-se pauta para uma variedade de disciplinas, expandindo, cada vez mais, seu espaço na agenda científica internacional, especialmente no Brasil. Ademais, destaca-se que a característica complexa da relação natureza(s)-sociedade(s) implica uma abordagem que reivindique maior integração e diálogo entre as mais diversas e diferentes áreas científicas, uma vez que a compreensão referente à questão ambiental tem transbordado as fronteiras disciplinares há muito consolidadas no âmbito da ciência. A segunda seção, "Disciplinarização do conhecimento e interdisciplinaridade (ambiental): contextos e definições”, elenca algumas importantes definições sobre o conceito de disciplinarização do conhecimento e de pesquisa interdisciplinar, sobretudo em relação ao que aqui se denomina de interdisciplinaridade ambiental. Já a terceira seção, "A interdisciplinaridade nos termos da democracia pluralista: uma possibilidade de definição a partir do conceito de agonismo de Chantal Mouffe”, abarca o principal objetivo deste trabalho, que é o de propor uma nova conceitualização à interdisciplinaridade no âmbito das ciências ambientais. Por fim, na seção "Uma ciência pósdisciplinar é possível?”, são tecidas algumas considerações conclusivas.

\section{A questão ambiental como objeto complexo e o caminho à interdisciplinaridade}

Eventos catastróficos para o ambiente, como o rompimento da Barragem de Mariana, em 2015, no distrito de Bento Rodrigues, e a de Brumadinho, em 2019, ambas situadas em Minas Gerais - ou até mesmo as grandes construções, como a Usina Belo Monte, construída na Bacia do rio Xingu, 
as recentes queimadas na Amazônia e no Pantanal brasileiro e as mudanças climáticas, dentre outros inúmeros acontecimentos, como o aquecimento global e todas as suas implicações políticas, culturais, econômicas e naturais, com graves consequências em escala mundial - mostram a centralidade e a urgência dos problemas ambientais no que tange à agenda da produção de conhecimento científico. Tal perspectiva enseja a necessidade de um amplo diálogo entre diferentes áreas da Ciência na busca de ferramentas e de estratégias epistemológicas, teóricas e metodológicas para a solução dos problemas complexos que caracterizam a relação sociedade(s)-natureza(s); problemáticas estas que, por seu turno, têm transbordado os limites impostos pela fragilidade do paradigma disciplinar e pela crise do projeto moderno de ciência.

Quando se fala em “crise da modernidade”, faz-se alusão à crise baseada na "falha" do "sonho" moderno de que a ciência e a técnica seriam responsáveis pelo controle completo da natureza pelo humano, garantindo a redenção e emancipação da humanidade frente a toda espécie de impedimentos ou contratempos naturais, com a descoberta de todos os seus segredos. Nesse ponto, os temas que envolvem a questão ambiental assumem vital importância para que se possa compreender de que maneira o "projeto moderno" tem encontrado dificuldades de se mostrar eficaz, criando lacunas políticas e epistemológicas no próprio campo científico. Tais fissuras, produto da crescente hiperespecialização do conhecimento, acabam criando novos espaços em direção a modelos mais complexos de interpretação do mundo fenomênico, sobretudo a partir de uma ciência complexa ou de uma ciência da complexidade, através da integração disciplinar, isto é, da interdisciplinaridade. Portanto, argumenta-se que os temas em torno do ambiente são complexos e não podem ser apreendidos se confinados ao isolamento das disciplinas acadêmicas, posto que as abordagens ambientais reivindicam olhares multifacetados, dos mais variados campos disciplinares.

Conforme a ONU Brasil (2018), o alto crescimento da população mundial desencadeia uma série de consequências e preocupações globais relativas à saúde, envelhecimento, migração em massa, urbanização, demanda por mais habitação, abastecimento e alimentos, acesso à água potável, crime transnacional, mudanças climáticas e disseminações de diversos tipos de

\footnotetext{
${ }^{5}$ Mais recentemente, parece ser mais conveniente falar em tecnociência, esta não apenas como a fusão ou convergência entre ciência e tecnologia, mas como um acontecimento que funciona no interior de uma sociedade (moderna), caracterizado pela interação e retroalimentação entre capitalismo, desenvolvimento industrial e produção de conhecimentos científicos e técnicas.
} 
doenças. Tais problemas, indubitavelmente, são parte da nova e complexa configuração da relação dos humanos com a natureza. Como identificar, compreender e solucionar as problemáticas destacadas fora de um contexto que leve em consideração o paradigma da complexidade? Se o crescimento demográfico tem sobrecarregado o ambiente, posto que também gera mais consumo, produção e, consequentemente, mais poluição, pode-se argumentar que há, dessa forma, um aumento da complexidade no mundo contemporâneo, no qual todos os fenômenos estão intimamente conectados e tecidos numa ampla rede de inter-relações socionaturais.

Ante o debate em torno da "questão ambiental", toma-se como pressuposto o seguinte argumento defendido por Almeida (2016, p. 12): "por que o ambiente se tornou uma verdadeira questão? Porque, fundamentalmente, ele configura uma interrogação institucionalizada que mobiliza e organiza as representações sociais”. Ou seja, para o autor, o ambiente torna-se um significativo componente do debate social, especialmente pelas implicações políticas, institucionais e representacionais que configuram a questão ambiental. Tais implicações podem ser percebidas, segundo Almeida, na criação de uma "opinião pública”, na influência do lobby ecologista, no desenvolvimento de órgãos governamentais ligados às questões do ambiente e na produção de um aparato técnico-burocrático em torno dos problemas ambientais.

Quando se lança olhares à questão ambiental, mais manifesta se torna a necessidade de sinergia entre as disciplinas para solucionar problemas complexos. De acordo com Bursztyn (2005), logo após os conhecidos "trinta anos gloriosos", os quais salientaram o processo virtuoso da economia mundial pós-Segunda Guerra Mundial, fatores como o consumismo, desperdício de energia e matéria-prima, exclusão social, deterioração ambiental, obsolescência programada de técnicas e produtos - dimensão da própria lógica de consumo atual - fizeram emergir aquilo que o autor denomina de "uma onda de reação ao modo como a tecnociência evoluía" (Bursztyn, 2005, p. 40). Tal onda diz respeito à sinalização, por parte de uma série de cientistas, de que era preciso a tomada de um novo rumo - até mesmo um novo paradigma - para o conhecimento científico, dado o reflexo do progresso da técnica e da tecnologia, tanto no mundo natural quanto nas relações sociais, como, por exemplo, a problemática ambiental acarretada por esse avanço. Com base nisso, a partir das décadas de 1960 e 1970, 
iniciativas e esforços têm sido forjados para que seja possível a construção de uma alternativa à prática disciplinar.

Ainda em tempo, o capitalismo industrial tem desencadeado uma série de impactos em todas as dimensões da vida cotidiana, em especial pelo crescimento econômico irrestrito e indiferenciado, conforme ressaltam Capra e Luisi (2014). Para esses autores, o círculo vicioso acarretado pela pressão demográfica e pela pobreza vem produzindo a escassez dos "recursos naturais", como, por exemplo, a redução no volume e a contaminação dos lençóis freáticos, a retração no crescimento das florestas, a erosão dos solos, além de toda problemática que envolve as mudanças climáticas (Capra \& Luisi, 2014). Assim, "a ilusão da viabilidade do crescimento ilimitado é mantida por economistas que se recusam a incluir os custos sociais e ambientais das atividades econômicas em suas teorias” (2014, p. 449). É a partir disso que Dowbor (2017) demonstra, baseado na World Wild Fund for Life (WWF), que, entre os anos de 1970 e 2010, 52\%, ou seja, mais da metade da fauna do planeta, foi destruída pela intervenção humana. ${ }^{6}$

Os acontecimentos mencionados demonstram a complexidade das diferentes dimensões que têm formado a tessitura do universo social nos últimos tempos. A velocidade das mudanças sociais, da tecnociência, com relação a períodos (séculos) anteriores, constitui-se fator que caracteriza um paradigma complexo (Coelho, 2015). A complexidade que subjaz às questões ambientais - dadas as inúmeras variáveis que podem e devem ser problematizadas por diversas áreas da ciência - tem transbordado os limites e as fronteiras disciplinares do conhecimento científico. Por isto, Leff afirma que

[a] problemática ambiental tem transbordado o campo dos paradigmas científicos e do conhecimento disciplinar. Por um lado, a problemática ambiental é consequência das formas de conhecimento do mundo, da objetivação da realidade e o domínio da natureza através da imposição de um logos, de uma razão na qual não só os valores têm sido marginalizados e subjugados, como também têm explorado a natureza e o homem em um afã dominador e produtivista (Leff, 2011, p. 329).

\footnotetext{
${ }^{6}$ O uso sem limites dos "recursos naturais", impulsionado pela lógica de produção e consumo da nova ordem industrial-capitalista, atrelado ao desenvolvimento veloz da tecnociência, tem gerado aquilo que o sociólogo alemão Ulrich Beck (2015) cunhou de "sociedade de risco". Esta é tida como uma etapa da modernidade, marcada pela incerteza, na qual a tecnociência assume papel preponderante na produção dos riscos; riscos que são produzidos industrialmente, externalizados economicamente, individualizados juridicamente, legitimados cientificamente e minimizados politicamente.
} 
Tal transbordamento ocorre devido às dimensões políticas, econômicas, ecológicas, entre outras, que permeiam a questão ambiental - enquanto objeto de investigação - em nível teórico, metodológico e epistemológico. Capra e Luisi (2014) argumentam que os mais destacados problemas (ambientais) de nosso tempo, como aqueles relativos à energia, mudanças climáticas, segurança alimentar, dentre outros, não podem ser compreendidos de forma isolada e restritos aos limites científicos disciplinares. Isso decorre, segundo esses autores, do fato de que tais problemas estão intimamente interconectados, são interdependentes e, portanto, complexos.

Por sua vez, Maranhão (2010) salienta que problemas mundiais, especialmente no que diz respeito à degradação ambiental, ultrapassam e transcendem as fronteiras disciplinares do conhecimento científico. Ainda para essa autora, a disciplinarização científica reduz a ação da ciência. Ademais, segundo Lélé e Norgaard (2005 apud Maranhão, 2010 p. 562), "para analisar problemas complexos como a questão ambiental é preciso pensar nas comunidades científicas sem se restringir aos saberes compartimentalizados em disciplinas curriculares”. Logo, se a complexidade do tecido social tem se mostrado cada vez maior, a ciência não tem ficado estática perante essa dinâmica, tornando-se, também, mais complexa. Tal característica reivindica uma nova postura científica que vá além dos sistemas únicos e que ultrapasse os limites do conhecimento herdados da analítica cartesiana, lançando, a partir disso, olhares para o universo socionatural de maneira plural, multifacetada e interdisciplinar (Coelho, 2015).

\section{Disciplinarização do conhecimento e interdisciplinaridade (ambiental): contextos e definições}

Falar em interdisciplinaridade implica, antes de tudo, definir, de modo geral, o que é "disciplina”. Esta palavra, ${ }^{7}$ segundo Rodrigues (2007), tem raiz latina e significa instrução, ensino e ciência. Em grego, o equivalente mais próximo é mathema, que remete à ideia de um objeto de aprendizado. Ainda para esse autor, a disciplinarização no contexto da ciência moderna surge a partir da marcante distinção, no século 17, entre os conhecimentos filosófico

\footnotetext{
${ }^{7}$ Discussões mais aprofundadas podem ser encontradas em Lenoir (2003), Wallerstein (1996), Rodrigues (2007), entre outros.
} 
e científico. Por conseguinte, o século 19 é caracterizado pela consolidação do processo de autonomização da ciência, entendida como ciência da natureza. Foi a partir desse século que o processo de diferenciação (formação de disciplinas) se mostrou intenso, tanto do ponto de vista epistemológico como institucional (Rodrigues, 2007). ${ }^{8}$

Conforme salienta Vinck (2014), as disciplinas remetem a uma dinâmica coletiva que tem por característica a produção de um sistema (conjunto) de elementos epistemológicos, metodológicos, linguísticos e organizacionais, comprometendo, assim, os movimentos de capitalização e também de estruturação "ao longo dos quais se constitui um núcleo duro, uma hierarquia, subdivisões e classificações” (Vinck, 2014, p. 94).

Quiçá uma das mais esclarecedoras definições sobre o conceito de disciplina - com "inspiração foucaultiana" - seja a de Lenoir.

As disciplinas são a infraestrutura da ciência corporificada (...) nos departamentos universitários, nas sociedades profissionais, nos manuais e livros didáticos (...). A disciplina ajuda a estruturar as relações dos cientistas com contextos particulares institucionais e econômicos. As disciplinas são os mecanismos institucionais para regular as relações de mercado entre consumidores e produtores de conhecimento. Elas são também instrumentos para distribuir status (...). São formações institucionalizadas para organizar esquemas de percepção, apreciação e ação, bem como para inculcá-los como ferramentas de cognição e comunicação (Lenoir, 2003, p. 65).

A definição de Lenoir possibilita um entendimento pormenorizado de como a produção de conhecimento científico está calcada na divisão e distanciamento entre disciplinas. Como demonstra esse autor, a disciplina caracteriza-se por ser a infraestrutura da ciência e assim o é desde a emergência da ciência moderna a partir do método analítico cartesiano ${ }^{9}$. Essa infraestrutura se materializa nas universidades, livros e manuais didáticos, uma vez que essa é a lógica, a cultura que determina como se produz ciência no Brasil e alhures. As disciplinas são, portanto, formações discursivas, regimes de verdade, construídas socialmente e atravessadas por

\footnotetext{
${ }^{8} \mathrm{Na}$ área da sociologia, a "disciplinarização" e construção institucional são tratadas, por exemplo, em Trindade (2018).

${ }^{9}$ Segundo Santos (2007, p. 15), ao referir-se aos postulados da ciência moderna, "conhecer significa dividir e classificar para depois poder determinar relações sistemáticas entre o que se separou”.
} 
relações de poder e hierarquia, as quais são responsáveis pelo caráter da ciência desunificada (Lenoir, 2003). Regimes de verdade, Lenoir os define, a partir de Foucault, como

(...) o corpo de práticas e os tipos de discurso que uma sociedade aceita e faz funcionar como verdadeiros; os mecanismos e instâncias que permitem a alguém, distinguir afirmações verdadeiras e falsas e os meios pelos quais cada uma delas é sancionada (...); o estatuto daqueles que são encarregados de dizer o que conta como verdade (Lenoir, 2003, p. 66).

Desse modo, a prática interdisciplinar, enquanto discurso e, consequentemente, regime de verdade que busca consolidar-se no campo científico, tem por princípio e função conjugar o conhecimento que o modelo disciplinar fragmentou, esperando contribuir, então, para o avanço da ciência. A própria “crise” dos pressupostos da analítica cartesiana faz emergir, afirma-se, dos anseios epistemológicos de parte da comunidade científica, a necessidade de se construir um novo fazer científico, uma nova racionalidade ou, como afirma Rodrigues (2017), uma nova cartografia disciplinar.

De acordo com Casanova (2006), a interdisciplinaridade, sobretudo a partir da Cibernética e da Teoria Geral dos Sistemas de Ludwig von Bertalanffy, nas décadas de 1940 e 1950, começa a vislumbrar um espaço no campo científico ${ }^{10}$ como processo e ferramenta na busca por solucionar problemas de natureza complexa, cujo atomismo disciplinar já não consegue mais resolver, uma vez que os fenômenos sociais e naturais transbordam as fronteiras rígidas das disciplinas.

Entretanto, foi a partir da década de 1970, com uma série de descobertas e eventos - Maio de 1968, os problemas ambientais cada vez mais recorrentes, o advento da sociedade do conhecimento, o surgimento da engenharia genética etc. -, que a interdisciplinaridade, de fato, entra na agenda da "ciência ocidental" com possibilidade de influenciar as disciplinas, a fim de buscar compreender os problemas do mundo contemporâneo. A

\footnotetext{
${ }^{10}$ Para Bourdieu (2013), o campo científico constitui-se um espaço de lutas simbólicas que se autonomizou (relativamente) do espaço social. Além disso, é um sistema constituído por relações objetivas entre posições adquiridas em lutas anteriores. É, segundo ele, um espaço de intensa competição entre os concorrentes do campo, ou seja, um campo formado por forças e por intensos conflitos, com o objetivo de conservar ou transformar o mesmo. Dessa forma, o que está em jogo, em disputa, são os monopólios da autoridade científica, esta que, por seu turno, diz respeito à "capacidade de falar e agir legitimamente, isto é, de maneira autorizada e com autoridade que são socialmente outorgadas a um agente determinado” (2013, p. 112).
} 
prática interdisciplinar, dessa maneira, tem buscado expandir os limites disciplinares, os quais o modelo analítico cartesiano produziu e consolidou ao longo dos últimos três séculos.

Casanova (2006) argumenta que, atualmente, não se pode pensar a natureza, a vida, a humanidade deixando de lado as grandes descobertas que emergiram a partir da cibernética, da epistemologia genética, da computação, dos sistemas autorregulados e autopoiéticos, do caos, dos atratores e dos fractais, ainda no século 20. Para ele, "a profundidade dessas descobertas (...) inclui novas formas de pensar e atuar que compreendem as chamadas ciências da complexidade e as tecnociências" (2006, p. 9). Ademais, para um esforço dessa magnitude, ao qual se deve integrar uma pluralidade de conhecimentos, a interdisciplinaridade ganha fôlego e torna-se uma alternativa viável - em nível teórico, epistemológico e metodológico -, porém não simples.

Rodrigues (2017, p. 305) afirma que a interdisciplinaridade é "filha” da necessidade de compreensão e enfrentamento de problemas complexos. Destaca o autor que "caso assim não o fosse, não haveria qualquer razão para que se transpusessem os 'limites seguros' das práticas disciplinares”. Tal perspectiva mostra o quanto a ciência tem se modificado e buscado, por intermédio da comunidade científica, novas formas e ferramentas de integração e diálogo, a fim de enfrentar a crescente dinâmica e complexidade dos fenômenos naturais e sociais do mundo contemporâneo. Casanova (2006) salienta, em uma mesma linha de raciocínio, que os movimentos favoráveis às pesquisas interdisciplinares criam possibilidades, as quais têm permitido redesenhar as velhas problemáticas no tocante à seleção de conhecimentos gerais "ou os da comunicação entre especialistas de distintos campos e que manejam distintas linguagens, técnicas, teorias e métodos” (2006, p. 29).

De acordo com Pombo (2006), a interdisciplinaridade, ademais de um plano puramente "ideal” de pesquisa e de compreensão da complexidade dos fenômenos, também é prática. Com base nisso, a autora argumenta que a interdisciplinaridade está presente, especialmente, no cotidiano da pesquisa. A pesquisa de cunho interdisciplinar corporifica-se nas mais variadas "experiências interdisciplinares, sejam elas puras ou aplicadas nas universidades, nos laboratórios, nos departamentos técnicos, na experimentação e institucionalização de novos sistemas de organização” (2006, p. 225). Corroborando este argumento, Leis (2005, p. 
03) ressalta que é "prudente evitar debates teórico-ideológicos sobre o que é interdisciplinaridade, sendo preferível partir da pergunta sobre como essa atividade se apresenta no campo acadêmico atual”, isto é, como a interdisciplinaridade ocorre no cotidiano da própria produção de ciência.

Frente ao exposto, Etges (2011) enfatiza que o fazer interdisciplinar possui o papel de mediar a compreensão científica, além de dar forma à cooperação em nível crítico e criativo entre os cientistas. Esse autor afirma também que a interdisciplinaridade se caracteriza por ser o princípio da compreensão da ciência para o cientista, assim como de suas perspectivas e de seus limites. "Portanto (...), ela é o impulso na busca de novos horizontes para a superação do atual constructo e a criação de um novo” (2011, p. 85). Ademais, a interdisciplinaridade, enquanto ferramenta epistemológica, teórica e metodológica para a pesquisa, conforme salienta Raynaut (2011), tem o papel central de produzir constantemente a dúvida e o processo de reconstrução em relação ao conhecimento.

Em se tratando da relação entre interdisciplinaridade e temas ambientais, Rocha (2003) afirma que a prática interdisciplinar, no âmbito universitário, angariou uma nova perspectiva mediante o debate em torno da questão ambiental, por todo o mundo, nas décadas de 1960 e 1970. Isso porque a problemática socioambiental reivindica, segundo ele, uma atitude de caráter inovador que produza uma sistemática de cooperação e de sinergia entre diversas e distintas áreas do conhecimento humano e científico. Nesse sentido, toma-se como pressuposto a definição desse autor sobre “interdisciplinaridade ambiental", usando-a como sinônimo de "ciências ambientais", quando o mesmo argumenta que ela é caracterizada pela reunião de pelo menos duas grandes áreas da ciência, a saber as ciências biológicas e as ciências humanas. Em suma, é característico da questão ambiental, enquanto objeto das ciências ambientais, a exigência de integração e cooperação entre uma série de pesquisadores das mais variadas disciplinas científicas, tais como a biologia, economia, geografia, engenharia, sociologia, antropologia, agronomia, direito, dentre outras não menos relevantes (Rocha, 2003). Para esse autor, então,

a interdisciplinaridade ambiental é um processo de pesquisa, de conhecimento, de levantamento, análise e síntese da realidade por diferentes campos disciplinares, em trabalho conjunto interligado por um objeto unificado: o de compreender e resolver problemáticas socioambientais (Rocha, 2003, p. 155). 
Consequentemente, por "interdisciplinaridade ambiental” entende-se a conjunção de ao menos duas disciplinas de áreas distintas, por exemplo, a biologia, no campo das ciências biológicas, e a história, no campo das ciências humanas. Tal cooperação faz emergir o diálogo e o "afrouxamento" das fronteiras disciplinares, o que possibilita expandir o olhar e a observação quando os pesquisadores se deparam com um problema de natureza complexa, como no caso de um acidente nuclear, de uma ocupação irregular em área ambiental protegida, de acidentes com barragens, como ocorreu em Mariana, em 2015 e em Brumadinho quatro anos depois. Colaborando com esse pressuposto de "interdisciplinaridade ambiental" e de "ciência integrativa”, Joly (2011, p. 11, grifos do autor) salienta que

sistemas ecológicos sociais exigem abordagens complexas, que utilizam muito mais do que a justaposição de ferramentas, conceitos e métodos oriundos de diversas disciplinas. Mas, certamente, é a ousadia da interpretação dos resultados que está forjando a base para esta 'nova iniciativa transdisciplinar que muitos acadêmicos estão denominando ciência ambiental e/ou pesquisa das interações homem-ambiente' (...). Esta iniciativa tenta construir uma "cara" para a expressão utilizada, até agora, de forma vaga e imprecisa: as dimensões humanas das mudanças globais.

Ainda em tempo, conforme explicitado por Moran (2011), a utilização abusiva dos "recursos naturais" encontra-se no centro dos debates e negociações internacionais, tanto no âmbito econômico quanto no político. Por isso, de acordo com o autor, essas negociações necessitam ser observadas e compreendidas a partir das ciências ambiental e social, ou seja, de uma ciência integrativa que aborde as dimensões biofísicas e sociais que dizem respeito à relação humanos-natureza(s), ou seja, a questão ambiental, enquanto objeto de natureza complexa, tem demandado maior compreensão de suas variadas dinâmicas e transformações mediante a interdisciplinaridade.

\section{A interdisciplinaridade nos termos da democracia pluralista}

Dentre os inúmeros modelos teóricos que emergiram nas décadas de 1960 e 1970, impulsionados, sobretudo, pelas amplas mudanças que se operavam à época, sobretudo no ocidente, a teoria do discurso representada por Ernesto Laclau e Chantal Mouffe, com suas bases fincadas no marxismo, na teoria 
da hegemonia de Gramsci, na psicanálise lacaniana, no pós-estruturalismo e na perspectiva de desconstrução pós-fundacionalista, ganha fôlego e destaque no cenário das ciências humanas e sociais. Rodrigues e Coelho (2016) argumentam que a teoria do discurso tem sido vastamente utilizada para o conhecimento detalhado de diferentes espaços sociais, mediante suas categorias de análise, especialmente a particular categoria de discurso. Ainda para esses autores, a teoria do discurso tem ganhado adeptos nas áreas da ciência política, educação, sociologia e antropologia, mostrando o seu caráter interdisciplinar ${ }^{11} \mathrm{e}$ alcance para a compreensão de problemas complexos no âmbito dessas disciplinas.

A partir da década de 1990, após o lançamento de Hegemonia e estratégia socialista em 1985, tanto Laclau quanto Mouffe seguiram com suas produções teóricas separadamente. Cada qual com sua peculiaridade, ambos mantiveram em suas reflexões a discussão sobre hegemonia e democracia radical (Mendonça, 2010). Segundo Mendonça (2010, p. 480), "parece ter havido uma divisão do trabalho, pelo menos tácita, entre ambos os autores, no sentido da divulgação dos seus principais aspectos teóricos e epistemológicos". Enquanto Laclau se preocupou em ampliar a noção de hegemonia, priorizando o debate com a psicanálise, o marxismo, a linguística e o pós-estruturalismo, dando ênfase à dimensão ontológica do político, Mouffe, ao se basear nas premissas de Hegemonia e estratégia socialista, como as noções de antagonismo e hegemonia, tem proposto um modelo teórico para tratar da dimensão política normativa, ou seja, da dimensão ôntica, do cotidiano da política, indicando, assim, o conceito de democracia agonista no âmbito de uma democracia radical e plural (Mendonça, 2010).

Com efeito, os principais pressupostos de Mouffe são produzidos a partir da diferenciação entre "política" e "político", sendo a primeira relacionada ao nível ôntico, no qual se dão as relações empíricas da atuação política, isto é, do cotidiano da política. Já o segundo diz respeito à dimensão ontológica, a qual representa o espaço do poder, do antagonismo e do conflito, da constituição da sociedade (Kozicki, 2015). Conforme Mendonça (2010), Mouffe, em seus recentes trabalhos, tem buscado se ancorar em duas grandes

\footnotetext{
11 "Em virtude de sua característica inter e transdisciplinar, esta perspectiva [da teoria do discurso] pós-fundacionalista e pós-marxista tem ganhado grande destaque no meio intelectual nos últimos anos, não apenas no campo da sociologia, mas também em áreas como história, ciência política, educação, filosofia, dentre outras áreas” (Da Silva et al., 2017, p. 18).
} 
críticas, a saber: (i) a crítica direcionada às teorias de cunho deliberativo ${ }^{12}$, especialmente aquelas de Rawls e Habermas, contrapondo estes últimos à formulação de um modelo teórico agonístico sobre democracia; e (ii) a crítica em relação à concepção deliberacionista que advoga a eliminação das relações de poder na política, com base no princípio racional da tomada de decisões e, até mesmo, do consenso. O banimento do conflito e do poder é, para ela, impossível, dado que é o próprio poder que fundamenta a dimensão ontológica do político (Mendonça, 2010).

Mouffe (2015) parte de uma crítica à visão pós-política que prega a concepção do consenso entre sujeitos e instituições, negando a dimensão antagonista do campo da política. Ela enfatiza sua discordância com tal pressuposto, alegando que seus "alvos principais serão aqueles do campo progressista que aceitam essa perspectiva otimista da globalização e que se tornaram defensores de uma forma consensual de democracia” (Mouffe, 2015, p. 1). Afirma a autora que não há, como pensam os teóricos liberais sobre democracia, a possibilidade de harmonia num campo discursivo. Se, por um lado, a perspectiva pós-política defendida pelos liberais adota uma postura em direção à eliminação da relação "adversarial” entre adversários ou entre "amigos x inimigos", por outro, Mouffe toma o caminho oposto, salientando que a distinção "amigo x inimigo", "nós x eles” é parte constituinte que forma a natureza conflituosa da política. Assim sendo, identidade política implica um "nós/eles". Implica o estabelecimento de uma diferença, diferença essa que se cria, muitas vezes, numa base hierárquica. Portanto, toda identidade é criada a partir da negatividade, daquilo que algo não é, tornando possível ela ser algo. Corroborando tal argumento, Mouffe (2015) destaca que

a especificidade da política democrática não é a superação da oposição "nós/eles", mas a forma diferente pela qual ela se estabelece. O que a democracia exige é que formulemos a distinção "nós/eles" de um modo que seja compatível com a aceitação do pluralismo, que é constitutivo da democracia moderna (Mouffe, 2015, p. 13).

\footnotetext{
12 "Em rigor, sua ideia central - de que na sociedade democrática, as decisões políticas devem ser alcançadas por meio de um processo de deliberação entre cidadãos iguais e livres - tem acompanhado a democracia desde o seu nascimento na Grécia do século V a.C. As formas de conceber a deliberação e a definição daqueles aptos a deliberar variaram enormemente, mas a deliberação tem por longo tempo desempenhado um papel central no pensamento democrático. O que se vê hoje, é, portanto, o renascimento de um tema antigo, não a inesperada emergência de algo novo" (Mouffe, 2005, p. 11).
} 
Dito isso, Kozicki (2015) afirma que a teoria da democracia edificada por Mouffe toma o antagonismo e o conflito como categorias seminais para compreensão do político, o que demonstra a centralidade do dissenso no que tange à democracia. Segundo Mouffe (2015), é somente a partir do reconhecimento da dimensão antagonística do nível político (ontológico) que será possível progredir na conceitualização da democracia. Ainda para a autora, embora os liberais tentem convencer que a singularidade da política democrática é a superação da distinção "nós/eles", o que a democracia realmente reivindica é a oposição "nós/eles" de uma maneira que seja compatível com a premissa da aceitação do pluralismo, o qual se coloca como a "essência" da democracia moderna.

Ademais, o conceito de hegemonia é de suma relevância nos pressupostos da teoria do discurso de Mouffe. Afirma ela que se faz necessário um modelo democrático que apreenda a natureza do político. Tal apreensão deve se dar através da produção de uma abordagem que destaque o poder e o antagonismo como centrais, uma vez que não se pode falar em processo hegemônico sem levar em consideração esses dois conceitos. Conforme Mouffe (2005), em Hegemonia e estratégia socialista, ela e Laclau destacavam que toda objetividade social ${ }^{13}$ é produto de atos de poder, ou seja, toda e qualquer objetividade social é política e deve demonstrar as características de exclusão que estruturam sua constituição. "Esse ponto de convergência - ou de arruinamento mútuo - entre a objetividade e o poder - é o que nós queremos dizer com hegemonia” (Mouffe, 2005, p. 19).

Portanto, a ordem política (o próprio discurso), nos termos da autora, caracteriza-se por ser a expressão de uma determinada hegemonia, de um modelo padrão singular no qual coexistem relações de poder. Por esse motivo, segundo Mouffe, a política, em sua dimensão prática, não pode ser apreendida como mera representação de interesses e identidades pré-constituídas, "mas como constituindo essas próprias identidades em um terreno precário e sempre vulnerável” (Mouffe, 2005, p. 19). A compreensão da natureza que constitui e produz poder significa que se deve abandonar, segundo Mouffe, a ideia de uma sociedade democrática onde imperem perfeitas relações de harmonia e transparência. No que diz respeito à relevância da hegemonia em sua teoria, a autora salienta que

\footnotetext{
13 “Toda sociedade é o resultado de um conjunto de práticas que tentam estabelecer ordem em um contexto de contingência” (Mouffe, 2015, p. 14).
} 
asseverar a natureza hegemônica de qualquer tipo de ordem social significa operar um deslocamento das relações tradicionais entre democracia e poder. De acordo com a abordagem deliberativa, quanto mais democrática uma sociedade, menos o poder será constitutivo das relações sociais. Se aceitarmos, contudo, que as relações de poder são constitutivas do social, então a questão principal para a política democrática não é como eliminar o poder, mas como constituir formas de poder mais compatíveis com valores democráticos (Mouffe, 2005, p. 19).

Ilustrando detalhadamente tal pressuposto, Mouffe afirma que o poder é parte constituinte do social, uma vez que este último não existiria caso as relações de poder não existissem, pois é a partir dessas relações de força e de poder que o social se formaliza. Para a autora, se, num dado momento, determinada verdade é tida como a ordem "natural" das coisas (hegemônica), isso se dá enquanto produto de práticas sedimentadas e nunca será possível ser a verdade uma objetividade completa, absoluta e externa às relações de práticas que lhe concebem forma. Desse modo, a ordem sempre é política e está calcada em determinadas formas de exclusão (Mouffe, 2015).

$\mathrm{Na}$ formação de determinado campo discursivo, outras possibilidades de verdade, de ordem, de discurso hegemônico foram suprimidas e, em algum momento, diz Mouffe (2015), podem ser reativadas, como se pode destacar no seguinte exemplo preparado para este artigo. Atualmente, a interdisciplinaridade aparece como um discurso contra-hegemônico em relação à hiperespecialização do conhecimento científico. Ela articula uma série de demandas da comunidade científica, que reivindica maior diálogo e sinergia entre diferentes áreas, a fim de compreender os problemas complexos da contemporaneidade. Assim, "a interdisciplinaridade, enquanto uma determinada ordem política, tem tomado a forma de um discurso contrahegemônico" (Coelho, 2020, p. 118). Porém, essa construção é contingente e, por conta disso, pode ser substituída por outra ordem a qualquer momento, como a "transdisciplinaridade", ${ }^{14}$ que formaria outro discurso, mostrando, com isso, que o campo discursivo só pode ser entendido em termos de precariedade e de contingência. Dessa maneira, “toda ordem hegemônica é possível de ser desafiada por práticas anti-hegemônicas, isto é, práticas

\footnotetext{
${ }^{14}$ Conforme Cruz e Costa (2015), não é possível afirmar um consenso generalizado sobre seu significado, dadas as inúmeras definições existentes.
} 
que tentarão desarticular a ordem existente para instalar outra forma de hegemonia” (Mouffe, 2015, p. 17).

Mouffe $(2005,2015)$ avança em sua proposta teórica, ao conceber o agonismo como elemento central para se entender a democracia pluralista e radical. Segundo ela, enquanto o antagonismo, amplamente utilizado por Laclau, significa a relação entre um "nós x eles", na qual os dois lados se colocam como inimigos, com nenhuma demanda em comum, o agonismo caracteriza-se por ser uma relação “nós x eles”, mas as partes em conflito reconhecem a legitimidade uma da outra, mesmo estando cientes de que não há possibilidade de qualquer solução racional ao conflito. As duas identidades em confronto não são inimigas, não querem aniquilar uma à outra, mas são, nesse sentido, adversárias, convivendo numa relação agônica. Assim, "a tarefa da democracia é transformar o antagonismo em agonismo" (Mouffe, 2015, p. 19). Além disso, os teóricos e políticos democráticos devem visualizar uma esfera pública agonística, na qual o conflito, a contestação e as relações de poder são constituintes da ordem política (discurso), em que inúmeros e divergentes projetos hegemônicos se confrontam (Mouffe, 2005).

O objetivo central de Mouffe com a formulação do conceito de "agonismo" é o de mostrar como o antagonismo pode ser transformado com vistas a criar uma maneira de oposição ("nós x eles") compatível com a democracia pluralista, ou seja, com o modelo que prioriza o olhar para as lutas agônicas da sociedade. Para ela, não é possível ultrapassar a lógica da relação "nós/ eles", pois isso cairia no consenso liberal ao qual a autora se opõe. Mouffe questiona: o que produziria uma relação de antagonismo "domesticada”? Qual forma de "nós/eles” isso implicaria? E ela mesmo responde: para que se torne legítimo, o conflito agônico deve assumir uma forma que não aniquile ou destrua o ente político. "Isso significa que é preciso existir algum tipo de vínculo comum [articulação] entre as partes em conflito para que elas não tratem seus oponentes como inimigos que devem ser erradicados”, ou que, tampouco, passem a considerar que seus objetivos e pretensões sejam ilegítimos, posto que isso é o que caracteriza a relação antagônica "amigo x inimigo" (Mouffe, 2015, p. 19).

Entretanto, Mouffe alerta para o fato de que não se pode confundir a dimensão agônica das relações de poder com a perspectiva na qual os oponentes possuem interesses que podem ser abordados a partir de uma mera negociação, "ou acomodados por meio da discussão, porque, nesse caso, o elemento agonístico teria sido simplesmente eliminado” (Mouffe, 
2005, p. 19). Com efeito, agonismo não significa negociações harmônicas, produzidas sem a presença de relações de poder e conflito. Muito ao contrário, as relações agônicas caracterizam-se por manter certo grau de tensão entre as diferentes e distintas partes que compõem determinado campo discursivo, constituindo-se, então, em relações entre adversários. Sobre isto, a autora argumenta que

o "adversário" é uma categoria crucial para a política democrática. O modelo adversarial tem de ser considerado constitutivo da democracia porque ele permite que a política democrática transforme antagonismo em agonismo. (...) Ele nos ajuda a imaginar como a dimensão do antagonismo pode ser "domesticada", graças ao estabelecimento de instituições e de práticas pelas quais o antagonismo potencial pode ser desenvolvido de forma agonística. (...) Enquanto houver canais políticos legítimos para que as vozes discordantes se manifestem, a probabilidade de surgirem conflitos antagonísticos é menor (Mouffe, 2015, p. 20).

Logo, a partir dessa citação, tem-se uma questão pertinente que guia as reflexões neste artigo: ${ }^{15}$ se o objetivo da democracia pluralista é o de "domesticar" o antagonismo e transformá-lo em agonismo, concebendo as diferentes práticas e instituições como adversários, não teria a pesquisa interdisciplinar a mesma função na ciência, posto que esta, assim como a democracia pluralista, não objetiva pôr fim aos conflitos, mas sim, aproximar as disciplinas sem que estas percam suas identidades? Considerase, em um exercício meramente experimental, substituir algumas palavras da citação acima mencionada por outras relacionadas à ciência para que se possa realizar um curto teste: o "adversário” é uma categoria crucial para a [pesquisa interdisciplinar]. O modelo adversarial tem de ser considerado constitutivo da [interdisciplinaridade] porque ele permite que a ciência interdisciplinar transforme antagonismo em agonismo. (...) Ele nos ajuda a imaginar como a dimensão do antagonismo pode ser “domesticada”, graças ao estabelecimento de práticas e instituições pelas quais o antagonismo potencial pode ser desenvolvido de forma agonística. (...) Enquanto houver

\footnotetext{
${ }^{15}$ É importante destacar que Chantal Mouffe não produziu um cabedal teórico voltado à ciência. Essa tentativa de relacionar o conceito de democracia pluralista e interdisciplinaridade é um dos principais balizadores deste artigo, tendo como perspectiva iniciar determinada provocação em direção a uma sociologia política da Ciência, com bases alicerçadas numa matriz epistemológica pós-fundacionalista e pós-estruturalista.
} 
canais [interdisciplinares] legítimos para que as vozes discordantes se manifestem, a probabilidade de surgirem conflitos antagonísticos entre [as disciplinas científicas] é menor.

Nesse sentido, entende-se que a pesquisa interdisciplinar (ambiental/ nas Ciências Ambientais) pode ser definida nos termos da democracia pluralista de Chantal Mouffe. Em termos práticos, para este trabalho, o que se quer expor é a seguinte ideia: não necessariamente as diferentes áreas, numa relação interdisciplinar no âmbito das Ciências Ambientais, estão articuladas para derrotar outro grupo de áreas numa relação radicalmente antagônica. É possível que o campo discursivo formado por elas seja muito mais constituído por agonismos, numa espécie de democracia pluralista nos termos de Chantal Mouffe.

Assim sendo, não poderia haver, todo tempo, num campo interdisciplinar, relações antagônicas, cujo objetivo seria o de derrotar o inimigo, de aniquilálo num sentido de destruição. Tomando como um exemplo próximo os programas de pós-graduação multidisciplinares em Ciências Ambientais (PPGMCA) brasileiros, fomentados pela CAPES desde 2011, o que pode ocorrer é um agrupamento de áreas, por meio dos pesquisadores que as representam, especialmente as ciências humanas, articulando-se com o propósito de sobrepujar alguns critérios de avaliação oriundos das agências de fomento brasileiras, pois estas parecem privilegiar outras áreas da ciência, como a biologia, por exemplo, em detrimento de outras no que diz respeito à questão ambiental. No mais, parece que essas áreas mantêm relações ora de cooperação, ora agônicas, formando uma democracia pluralista no âmbito de tais programas (Coelho, 2020).

Para melhor ilustrar o argumento salientado acima, faz-se necessário trazer à baila um sintético recorte do campo empírico utilizado em Coelho $(2020)^{16}$ e que dá suporte a este artigo. Um dos entrevistados - docente de Sociologia de um PPGMCA brasileiro - afirma, em relação à valorização e ao papel da Sociologia Ambiental no seu programa, que esta última possui certo grau de valorização.

Essa valorização não era de início assim, acho que foi uma conquista da área. Acho que hoje tem um respeito, acho que a gente tem dado uma contribuição no sentido de mostrar a importância do social, do

\footnotetext{
${ }^{16}$ Pesquisa realizada com o objetivo de mapear e identificar as disputas políticas e epistemológicas a partir das articulações discursivas da sociologia ambiental nos PPGMCA de excelência brasileiros.
} 
psicológico, do antropológico etc. para a compreensão das questões ambientais. Acho que a gente demonstrou pra eles em algumas pesquisas que técnicas da biologia e de outras áreas poderiam obter resultados muito parecidos de forma mais rápida com os métodos das ciências humanas (Coelho, 2020, p. 157).

Quando o entrevistado faz referência ao "nós”, sociólogos e antropólogos, pesquisadores das ciências humanas em geral, e ao "eles", biólogos e outras áreas afins, destaca-se uma evidente construção de um limite discursivo, um corte agônico e até mesmo antagônico entre as ciências humanas e as ciências biológicas, a depender das demandas que surgem. Frente a isso, pode-se inferir que, mesmo cooperando em um determinado projeto de pesquisa ou em outra situação, a fronteira que demarca as identidades disciplinares ou o grupo de disciplinas do qual o pesquisador faz parte parece ficar bem estabelecida. É o “nós” aqui e o “eles” ali. Ou seja, há cooperação, acordos e até certos tipos de consensos, desde que não se ultrapasse as demarcações construídas pelos conflitos inerentes a essas relações disciplinares.

Tal concepção, acima retratada, está baseada na perspectiva sobre o conceito de agonismo de Mouffe (2015), para quem a tensão entre "nós" x “eles” é parte constituidora da natureza política. O agonismo é a própria luta adversarial. Logo, afirma-se que não existe política e, portanto, ciência, sem que haja conflito entre as partes que formam determinado campo discursivo/ disciplinar. Nesse sentido, ainda conforme a autora, toda identidade política alude à relação “nós x eles”, bem como ao estabelecimento de uma diferença, posto que toda identidade, especialmente para a teoria do discurso, está fundada na negatividade, ou seja, a identidade de determinado grupo é concebida a partir daquilo que esse grupo não é. Esta característica de não ser algo é o que faz com que a identidade venha a ser outro algo, ou seja, só existe um "nós" na medida em que existe um "eles".

\section{Uma ciência pós-disciplinar é possível?}

Conforme visto no decorrer deste artigo, foi possível observar que as acepções referentes à interdisciplinaridade variam de acordo com quem a define, seja por teóricos ou por pesquisadores que lidam com a pesquisa interdisciplinar no seu cotidiano. Isso ocorre porque, assim como em todos os discursos (no âmbito da teoria do discurso ora utilizada aqui), a 
interdisciplinaridade também se apresenta como um significante vazio que, segundo Laclau (2011, p. 71), se caracteriza por esvaziar-se "de todo vínculo com significados particulares" em busca de hegemonia, aglutinando uma série de demandas (científicas). É um significante desvinculado de todo e qualquer conteúdo semântico especial e que pode representar e aglutinar uma série de significados ao longo da história, pois sempre está em constante disputa para ser preenchido por determinado sentido que nunca será possível de forma última e absoluta.

Tendo em vista tal condição da interdisciplinaridade enquanto significante vazio, propõe-se pensar a pesquisa interdisciplinar como Chantal Mouffe define seu conceito de democracia pluralista. Nesse sentido, entende-se a interdisciplinaridade ambiental como um discurso, no qual as articulações e rearticulações discursivas são produzidas a partir das tensões e conflitos agônicos e antagônicos existentes entre as áreas científicas que formam o campo da discursividade (da ciência), isto é, através de uma lógica adversarial constituída na relação entre um "nós” x “eles”. Logo, só se poderia pensar em interdisciplinaridade levando em consideração a dimensão agonista e a possibilidade antagônica de todo e qualquer discurso, bem como sua contingência e precariedade.

Dessa maneira, propõe-se pensar a interdisciplinaridade ambiental como um locus político permeado de conflitos e lutas adversariais, agônicas - ou até mesmo antagônicas em torno de determinadas demandas -, cujo objetivo é a hegemonização, a universalização discursiva de certos nichos disciplinares. Especificamente no caso das pesquisas interdisciplinares ambientais, cujo objeto central é o ambiente, a principal busca de significado e preenchimento de sentido gira em torno de definir qual disciplina ou que conjunto de disciplinas pode melhor entender e explicar a natureza complexa que caracteriza a questão ambiental enquanto objeto científico. Isto é, quais grupos disciplinares (ou, mesmo, qual disciplina isolada) vão representar e universalizar as demandas das ciências ambientais e, assim, apresentar-se como aqueles que configuram, em si mesmos, a própria ciência ambiental. Essa tentativa de universalização e hegemonia é a mola propulsora para o funcionamento de todo e qualquer campo discursivo, seja ele no âmbito da pesquisa interdisciplinar ambiental ou fora dela.

Uma definição que melhor abarque a complexidade da pesquisa interdisciplinar necessita levar em consideração a concepção de pluralismo 
disciplinar, numa espécie de "harmonia antipolítica”, nos termos de Mouffe (2018), na qual a possibilidade de formações antagônicas e agônicas é sempre presente, mesmo que o viés da pesquisa interdisciplinar seja a integração e o diálogo. Todavia, reforça-se que integração e diálogo, enquanto características principais das pesquisas interdisciplinares, não significam puro consenso e, portanto, um espaço pós-político e pós-disciplinar, como já mencionado. Ao contrário, por possuir a relação de interação política e epistemológica como principal característica é que a interdisciplinaridade ambiental, pensada como uma democracia pluralista, é perpassada por conflitos adversariais entre diversos e distintos grupos disciplinares que formam determinado espaço interdisciplinar em busca de hegemonia e poder, seja num projeto de pesquisa ou num programa de pós-graduação em ciências ambientais.

Finalizando, a partir desta proposta de definição ora sugerida ao conceito de interdisciplinaridade ambiental, não há, portanto, espaço para pensar uma suposta "pós-disciplinaridade" (uma ciência sem disciplinas ou uma “transdisciplinaridade”), assim como não é possível, segundo Mouffe, pensar em pós-democracia, ou seja, pensar uma sociedade política sem conflito, baseada exclusivamente no consenso. A ciência nasce disciplinar a partir do cartesianismo e isso a caracteriza desde então. A interdisciplinaridade, definida como uma democracia pluralista, só é possível, enquanto discurso, por meio das relações de tensão e de conflito entre as diversas áreas do conhecimento científico. Discorrer sobre uma ciência "pós-disciplinar” ou "sem disciplinas" implicaria cair na mesma posição adotada pelos liberais pós-democráticos, que acreditam numa sociedade política livre de conflitos. Da mesma forma que Mouffe aponta discordância em relação a esse consenso liberal pós-político, nossa crítica repousa sobre aqueles que adotam a postura de que uma ciência transdisciplinar ou pós-disciplinar é possível.

\section{Referências}

Almeida, Jalcione. (2016). Pesquisa social sobre ambiente: misturando sujeitos e objetos híbridos. In J. Almeida (Org.), Conflitos ambientais e controvérsias em ciência e tecnologia (pp. 11-26). Editora da UFRGS.

Beck, Ulrich. (2015). A sociedade de risco mundial: em busca da segurança perdida. Editora 70. 
Bourdieu, Pierre. (2013). O campo científico. In R. Ortiz (Org.), A sociologia de Pierre Bourdieu (pp. 112-143). Olho d’Água.

Bursztyn, Marcel. (2006). A institucionalização da interdisciplinaridade e a universidade brasileira. Liinc em Revista, 1(1), 38-53. https://doi. org/10.18617/liinc.v1i1.188

Capra, Fritjof, \& Luisi, Pier L. (2014). A visão sistêmica da vida: uma concepção unificada e suas implicações filosóficas, políticas, sociais e econômicas. Cultrix.

Casanova, Pablo G. (2006). As novas ciências e as humanidades: da academia à política. Boitempo.

Coelho, Gabriel B. (2020). Lutas por hegemonia: articulações discursivas na sociologia ambiental nos Programas de Pós-Graduação Multidisciplinares de excelência em Ciências Ambientais. [Tese de Doutorado, Universidade Federal do Rio Grande do Sul]. Disponível em https://lume.ufrgs.br/handle/10183/213009

Coelho, Gabriel B. (2018, out.). A sociologia ambiental e seu espaço políticoepistemológico na pesquisa multidisciplinar em ciências ambientais no Brasil. In F. I. Campos (Org.). IX Simpósio Nacional de Ciência e Meio Ambiente. Simpósio realizado no III Congresso Nacional de Pesquisa, Ensino e Extensão - CIPEEX, Anápolis, 2018. Disponível em http:// anais.unievangelica.edu.br/index.php/CIPEEX/article/view/3088

Coelho, Gabriel B. (2015). Capes e o fomento aos Programas de Pós-Graduação Interdisciplinares: um olhar a partir dos Estudos Sociais da Ciência. [Dissertação de Mestrado, Universidade Federal de Pelotas.

Cruz, Elisabete, \& Costa, Fernando A. (2015). Formas e manifestações da transdisciplinaridade na produção científico-académica em Portugal. Revista Brasileira de Educação, 20(60), 195-213. https://doi. org/10.1590/S1413-24782015206010

Da Silva, Luis G. T. et al. (2017). A teoria do discurso de Ernesto Laclau como instrumento teórico da compreensão dos fenômenos sociais políticos e sociais. In L. G. T. da Silva et al. (Orgs.), Pós-Estruturalismo e teoria do discurso: a obra de Ernesto Laclau a partir de abordagens empíricas e teóricas (pp. 15-22). CRV.

Dowbor, Ladislau. (2017). A era do capital improdutivo: a nova arquitetura do poder sob dominação financeira, sequestro da democracia e destruição do planeta. Autonomia Literária.

Etges, Norberto J. (2011). Ciência, interdisciplinaridade e educação. In A. P. Jantsch \& L. Bianchetti (Orgs.), Interdisciplinaridade: para além da filosofia do sujeito. Vozes. 
Joly, Carlos A. (2011). Apresentação à edição Brasileira. In E. F. Moran, Meio ambiente e ciências sociais: interações homem-ambiente e sustentabilidade (pp. 11-14). Editora Senac.

Kozicki, Katya. (2015). Prefácio à edição brasileira. In C. Mouffe, Sobre o político (pp. vii-xviii). WMF Martins Fontes.

Laclau, Ernesto. (2011). Emancipação e diferença. EDUERJ.

Leff, Enrique. (2011). Complexidade, interdisciplinaridade e saber ambiental. Olhar de professor, 14(2), 309-335. https://doi.org/10.5212/ OlharProfr.v.14i2.0007

Lenoir, Timothy. (2003). Instituindo a ciência: a produção cultural das disciplinas científicas. Unisinos.

Maranhão, Tatiana P. A. (2010). Produção interdisciplinar de conhecimento científico no Brasil: temas ambientais. Sociedade \& Estado, 25(3), 561580. https://doi.org/10.1590/S0102-69922010000300008

Mendonça, Daniel. (2010). Teorizando o agonismo: crítica a um modelo incompleto. Sociedade \& Estado, 25(3), 479-493. https://doi. org/10.1590/S0102-69922010000300004

Moran, Emílio F. (2011). Meio ambiente e ciências sociais: interações homemambiente e sustentabilidade. Editora Senac.

Morin, Edgar. (2006). Abertura. In G. Castro, E. A. Carvalho \& M. C. Almeida (Orgs.), Ensaios de complexidade (pp. 11-12). Sulina.

Mouffe, Chantal. (2018). Por un populismo de izquierda. Siglo XXI.

Mouffe, Chantal. (2015). Sobre o político. WMF Martins Fontes.

Mouffe, Chantal. (2005). Por um modelo agonístico de democracia. Revista de Sociologia Política, 25, 11-23.

ONU Brasil. A ONU e a população mundial. NaçõesUnidas.org. Acessado em 15 set. 2018 em https://nacoesunidas.org/acao/populacao-mundial/

Pombo, Olga. (2006). Práticas interdisciplinares. Sociologias, 8(15), 208-249. https://doi.org/10.1590/S1517-45222006000100008

Raynaut, Claude. (2011). Interdisciplinaridade: mundo contemporâneo, complexidade e desafios à produção e à aplicação de conhecimentos. In A. Philippi Jr \& A. J. Silva Neto, Interdisciplinaridade em ciência, tecnologia e inovação (pp. 69-105). Manole. 
Rocha, Paulo E. D. (2003). Trajetórias e perspectivas da interdisciplinaridade ambiental na pós-graduação brasileira. Ambiente \& Sociedade, 6(2), 155-182. https://doi.org/10.1590/S1414-753X2003000300010

Rodrigues, Leo P. (2017). A impossibilidade da interdisciplinaridade: apontamentos para alternativas socioconstrutivistas. Ciências Sociais Unisinos, 53(2), 300-308. https://doi.org/10.4013/csu.2017.53.2.14

Rodrigues, Leo P. (2007). Obstáculos epistemológicos e sociológicos à interdisciplinaridade. In L. P. Rodrigues (org.), Sociedade, conhecimento e interdisciplinaridade: abordagens contemporâneas (v. 1, p. 19-46). Universidade de Passo Fundo.

Rodrigues, Leo P., \& Coelho, Gabriel B. (2016). A teoria do discurso como possibilidade de compreensão do campo curricular nesta contemporaneidade. In E. S. Leite, G. C. Massau, \& W. H. G. Soto (orgs.), Teorias e práticas sociológicas (v. 1, pp. 29-47). Max Limonad.

Santos, Boaventura de S. (2007). Um discurso sobre as ciências. Edições Afrontamento.

Trindade, Hélgio. (2018). "Disciplinarização” e construção institucional da sociologia nos países fundadores e sua reprodução na América Latina. Sociologias, 20(47), 210-256. https://doi.org/10.1590/15174522$\underline{020004707}$

Vinck, Dominique. (2014). Ciencias y sociedad: sociologia del trabajo científico. Gedisa.

Wallerstein, Immanuel. (1996). Para abrir as ciências sociais. Cortez.

\section{(cc) $\mathrm{BY}$}

Licenciado sob uma Licença Creative Commons Attribution 4.0 